\title{
KOMPARASI PENGGUNAAN ALGORITMA SUPPORT VECTOR MACHINE DENGAN PARTICLE SWARM OPTIMIZATION DALAM MEMPREDIKSI SUHU UDARA
}

\author{
Muhammad Rusdi \\ Fakultas Teknologi Informasi \\ Universitas Islam Kalimantan Muhammad Arsyad Al Banjari banjarmasin \\ rusdimuhammad001@gmail.com
}

\begin{abstract}
ABSTRAK
Algoritma yang dapat dipakai untuk memprediksi data suhu udara,ada yang sebagian yang sudah diketahui algoritma mana yang memiliki kinerja lebih akurat dan sebagian lagi belum di uji kinerja akurasi dari algoritma tersebut. Untuk hal tersebut algoritma perlu diuji untuk mengetahuinya. Metode yang diusulkan adalah SVM-PSO .metode ini di bandingkan dengan algoritma SVM,SVM-PSO yang sudah di uji akurasinya untuk prediksi data suhu udara. Algoritma yang akan diuji adalahSVM-PSO dan SVM, yang digunakan untuk prediksi suhu udara. Masing-masing algoritma akan implementasikan dengan menggunakan RapidMiner 5.3.Pengukuran kinerja dilakukan dengan menghitung rata-rata error yang terjadi melalui besaran Root Mean Square Error (RMSE). Semakin kecil nilai dari masing-masing parameter kinerja ini menyatakan semakin dekat nilai prediksi dengan nilai sebenarnya. Dengan demikian dapat diketahui algoritma yang lebih akurat.
\end{abstract}

Kata Kunci: Suhu Udara, RMSE, support vector machines,svm-pso prediksi suhu udara.

\section{PENDAHULUAN}

Suhu udara adalah keaadan panas atau dingin nya udara. Alat untuk mengukur suhu udara atau derajad panas disebut termometer. Pengukuran biasa dinyatakan dalam skala Celsius ( C ),Reamur ( R ), dan Fahrenheit ( F).

Suhu udara tertinggi di permukaan bumi adalah di daerah tropis (sekitar ekutor) dan makin ke kutub makin dingin.pada waktu kita mendaki gunung, maka suhu udara terasa dingin saat ketinggian bertambah . Tiap kenaikan bertambah 100 meter, suhu udara berkurang ( turun ) rata - rata $0,6^{\circ} \mathrm{C}$. Penurunan suhu udara semacam ini disebut gradien tempratur vertikel atau lapse rate. Pada udara kering, besar lapse rate adalah $1^{\circ} \mathrm{C}$.Keadaan panas suhu udara disebab kan oleh matahari.Faktor- faktor yang menpengaruhi banyak sedikit nya panas matahari yang diterima oleh bumi adalah keadaan awan,sudut sinar datang,dan lama nya penyinaran matahari. Kalimatan Selatan ibu kota banjarmasin dengan luas wilayah 57.785.50 kilometer persegi[1]. Banjarmasin merupakan suatu wilayah yang beriklim tropis suhu udara banjarmasin berkisar sekitar $24^{\circ} \mathrm{C}-32^{\circ} \mathrm{C}$.Akan diadakan Prediksi suhu udara diwilayah banjarmasin[2]. Mesin support vector ( SVM ) adalah metode pembelajaran mesin 
berdasarkan teori belajar statistik dan dapat memecahkan non - linear yang tinggi,regresi,dll di ruang sampel dan juga dapat di gunakan sebagai alat identifikasi sistem prediksi dengan cara rekonstruksi ruang fase,itu menetap kan model SVM sampel input /output dengan seri sampel limpasan kecil, set up model SVM memiliki kemampuan generalisasi yang kuat dan hasil prediksi yang memuaskan.Secara efektif memecahkan masalah seperti sampel kecil,lebih-learning,dimensi

tinggi,minimum lokal,dll prediksi masa depan tren limpasan evolusi dengan model ini akan memberikan dasar prediksi udara.

Iklim dapat di definisikan sebagai kondisi rata-rata suhu udara, curah hujan, tekanan udara, arah angin, kelembaban udara dan prameter iklim lain nya dalam jangka waktu yang panjang. Apaila terjadi perubahan dari kondisi rata-rata prameter iklim, maka hal tersebut di katakan sebagai perubahan iklim.Perubahan iklim tidak terjadi secara mendadak atau dalam jangka waktu yang singkat, tetapi berlangsung secara perlahan dalam jangka waktu yang panjang.

Support Vector Machine berbasis Particle swarm optimization (SVM + PSO) adalah metode pencarian berbasis solusi secara acak yang disebut partikel.mampu mengoptimal kan nilai akurasi[3].oleh karena itu saya disini akan melakukan prediksi suhu udara menggunakan algoritma Support vector machine berbasis particle swarm optimization.supaya nilai akurasi yang lebih akurasi yng sangat akurat.

\section{METODE PENELITIAN}

Metode penelitian yang dilakukan adalah metode penelitian eksperimen, dengan tahapan penelitian seperti berikut:

1. Pengumpulan Data (Data Gathering)

2. Pengolahan Awal Data (Data Pre-processing)

3. Model/Metode Yang Diusulkan (Proposed Model/Method)

Metode yang diusulkan adalah metode perbandingan tingkat akurasi dari model algoritma soft computing yang dapat digunakan untuk memprediksi Suhu Udara.

4. Eksperimen dan Pengujian Metode (Method Test and Experiment)

Masing-masing algoritma akan menggunakan data yang identik. Sebagian data digunakan sebagai data training dan sebagian lagi sebagai data checking. Perhitungan dengan masingmasing algoritma akan diulang beberapa kali untuk mendapatkan besaran parameter terbaik.

5. Evaluasi dan Validasi Hasil(Result Evaluation and Validation)

Evaluasi dilakukan dengan mengamati hasil prediksi menggunakan algoritma softcomputing. Validasi dilakukan dengan mengukur hasil prediksi dan juga dibanding dengan algoritma lain. Pengukuran kinerja dilakukan dengan membandingkan nilai error hasil prediksi masing-masing algoritma sehingga dapat diketahui algoritma yang lebih akurat. 


\section{PEMBAHASAN}

\section{Eksperimen dan Pengujian}

\section{Model/Metode}

Algoritma yang diusulkan dalam penelitian ini akan diterapkan pada data Suhu Udara pada tahun 20102014 yang didapatkan dari instansi BMKG Banjarbaru Kalimantan selatan. Untuk membandingkan Support Vector Machines dengan Support Vector Machines Berbasis Particle swarm optimization dalam penelitian ini di terapkan pada data Prediksi suhu udara dari tahun 20102014. Data Suhu Udara ini akan di proses menggunakan Rapidminer.

\section{Model Support Vector Machines(SVM)}

Model design Support Vector Machine (SVM) menggunakan rapidminer menggunakan Read Excel, windowing,Set Role, Validation. Adapun Design model yang di gunakan dalam rapidminer sebagai berikut :

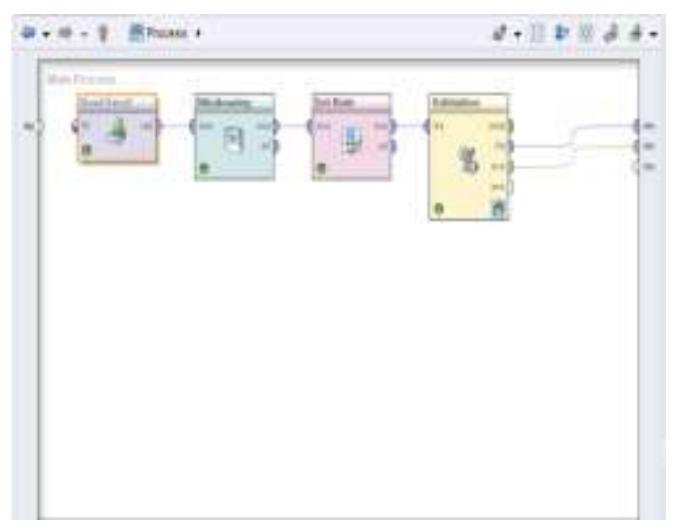

Gambar 4.1 design SVM di Rapidminer

Untuk design di dalam Validasi di masukan default Model untuk Data Traning, dan untuk Data testing dimasukan Apply Model dan
Performansce. Dari performance di hasilkan akurasi berupa Root Mean Square Error (RMSE). Design model rapidminer sebagai berikut :

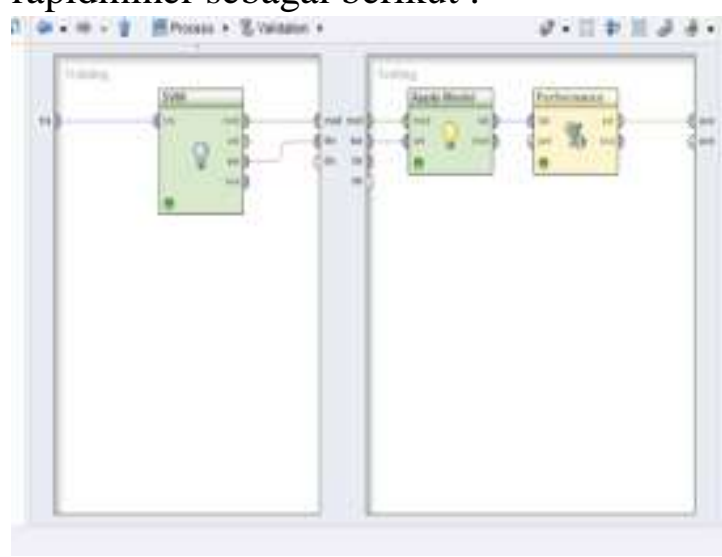

Gambar 4.2 Design SVM di dalam X Validation

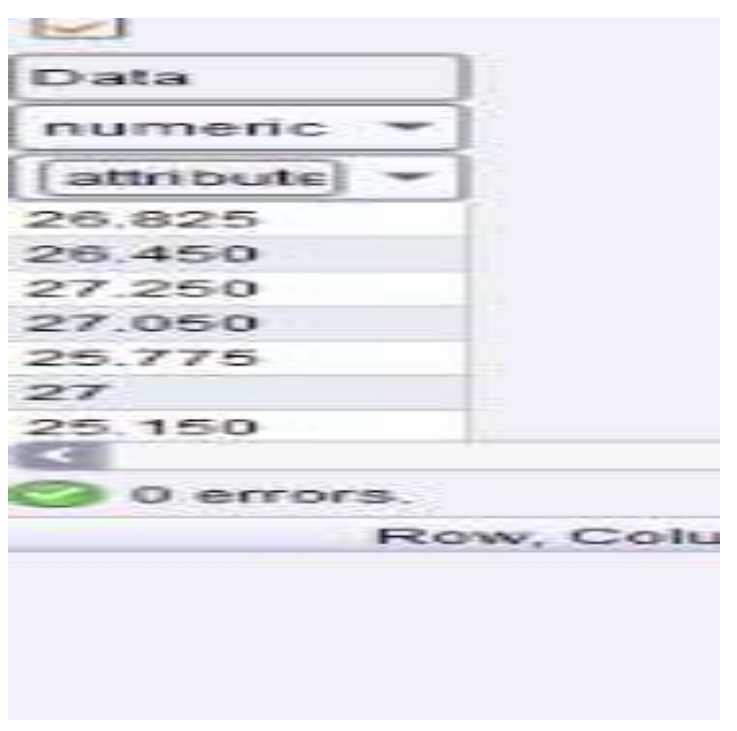

Gambar 4.3 Atribut Data di rubah menjadi label untuk SVM

Gambar di atas menjelaskan atribut Data' di rubah menjadi label, ini sebagai target untuk di prediksi menggunakan Support Vector Machine. 
Hasil dari percobaan di Rapidminer berupa root Means Square Error sebagai berikut :

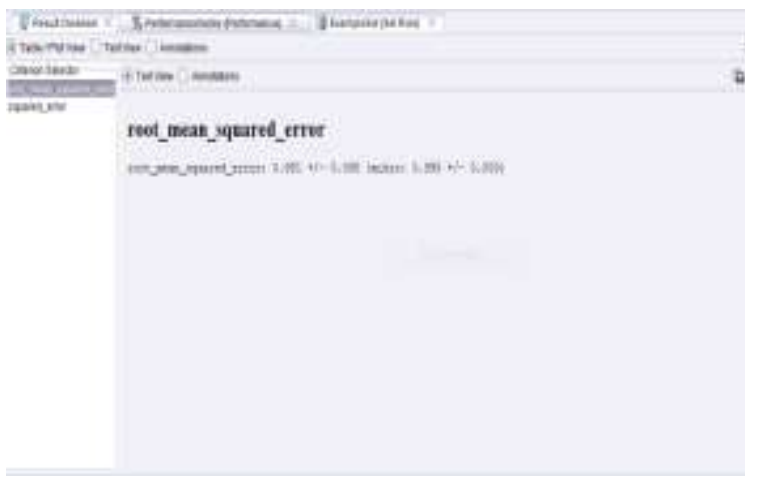

Gambar4.4 Hasil RMSE SVM

Hasil dari proses Rapidminer menggunakan Support Vector Machine menghasilkan RMSE 0.991.

\section{Model Support Vector Machine dengan Support Vector Machine Berbasis Particle Swarm} Optimization

Design model Support Vector Machines Berbasis Particle Swarm Optimization menggunakan rapidminer menggunakan Read Excel, windowing,Set Role, Optimize waigths (pso). Adapun Design model yang di gunakan dalam rapidminer diperlihatkan seperti gambar dibawah ini.

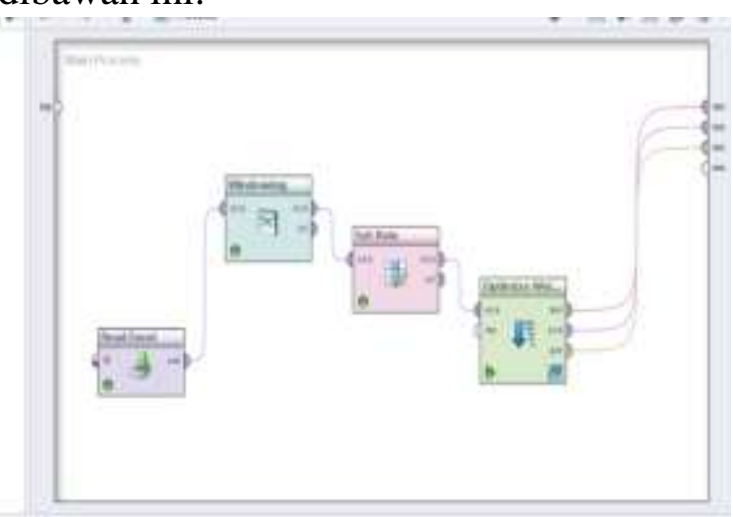

Gambar 4.5 Design model SVM - PSO
Gambar di atas adalah design keseluruhan Support Vector Machines Berbasis Particle Swarm Optimization yang dibuat di Rapidminer

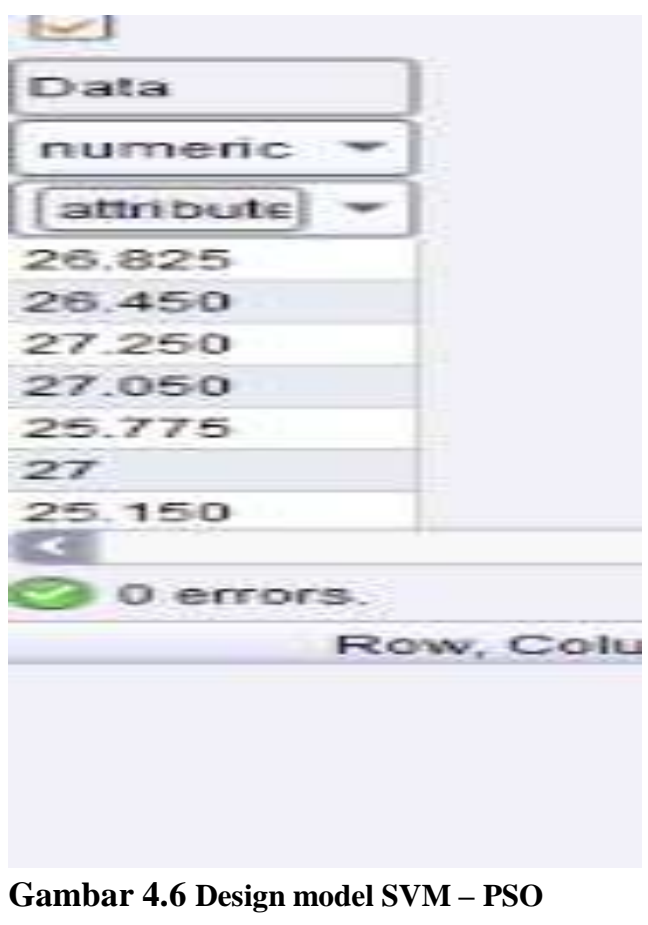

Gambar di atas menjelaskan atribut Data' di rubah menjadi label, ini sebagai target untuk di prediksi menggunakan Support Vector Machines Berbasis Particle Swarm Optimization.

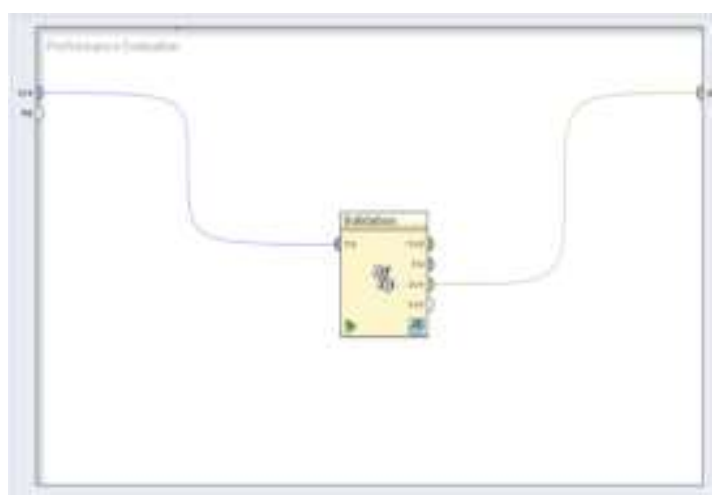

Gambar 4.7 Design model di dalam $X$ Validasi 
Di dalam Optimize Weights (PSO) ber isi $\mathrm{X}$ Validasi yang ada di rapidminer.

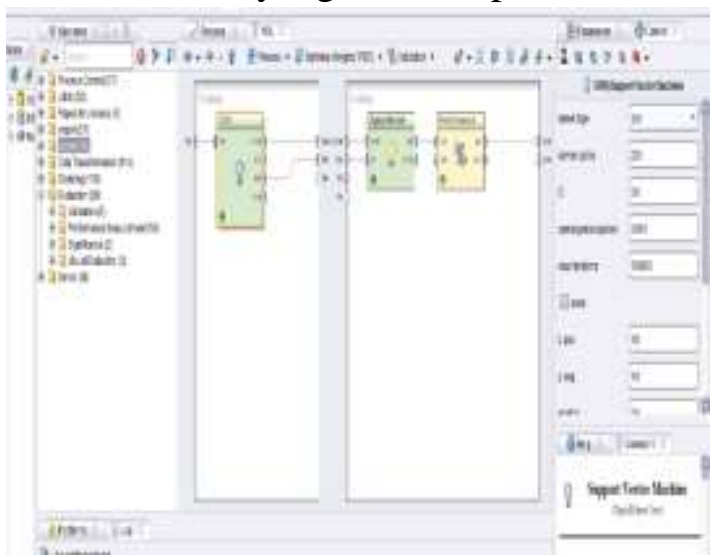

Gambar4.7 Design model di dalam X Validasi

Dari gambar diatas diperliahatkan untuk mengukur akurasi di buat design validasi, di dalam validasi terdapat SVM sebagai traning dan Apply model serta performance untuk testing.

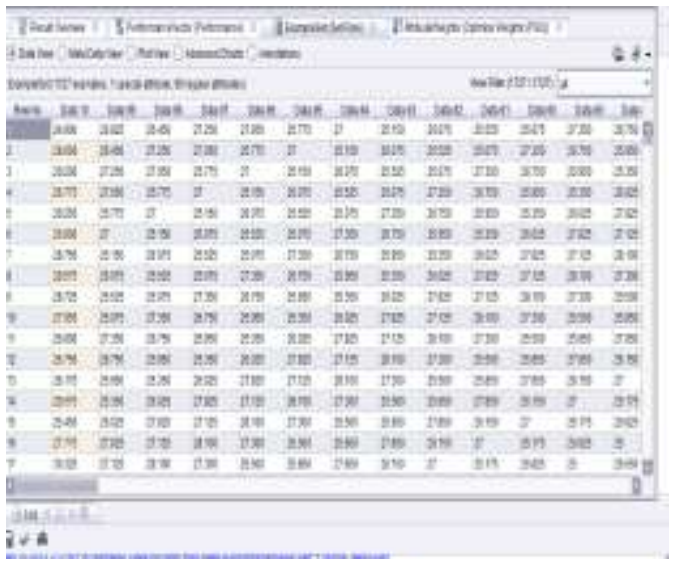

Gambar 4.9 Design model di dalam X Validasi

Dari gambar diatas diperliahatkan untuk hasil prideksi suhu udara di buat design data view, di dalam terdapat nilai Example set (set rule).

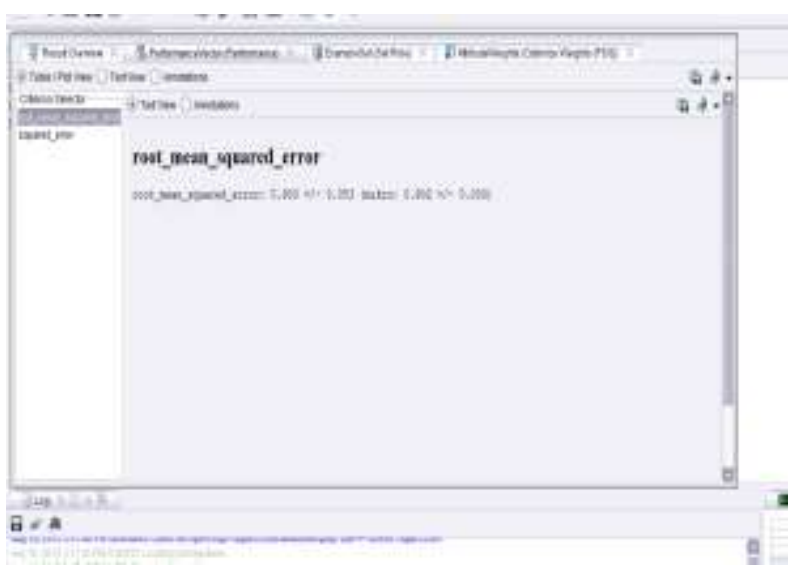

Gambar 4.10 Hasil RMSE dari SVM - PSO

Hasil RMSE 0.902 di perlihatkan dari gambar 4.11 diatas.

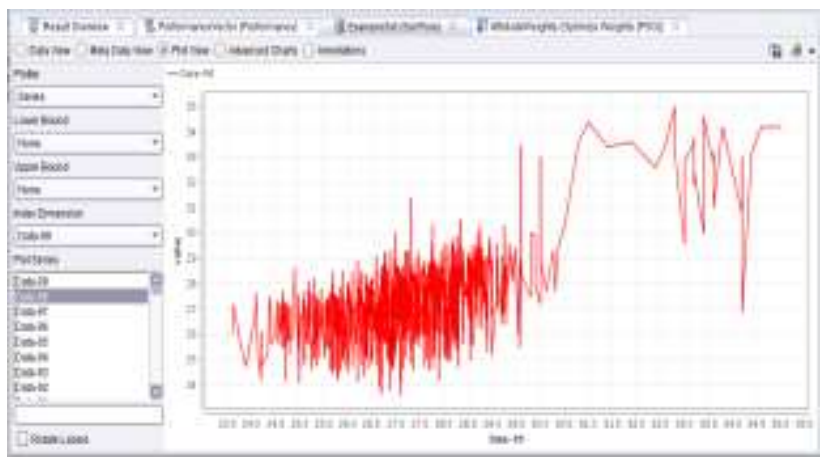

Gambar4.11 Prediksi SVM-PSO

Hasil grafik 4.1 prediksi yang dihasilkan dari SVM-PSO dilihat dari grafik diatas.

\section{Support Vector Machines}

Hasil penelitian ini menghasilkan Root Mean Squered Error (RMSE) dari algoritma Support Vector Machines pada tabel 4.1.3

Tabel Error! No text of specified style in document..1 Nilai RMSE 


\begin{tabular}{|c|c|}
\hline $\begin{array}{l}\text { X- } \\
\text { validasi }\end{array}$ & RMSE \\
\hline 2 & 1,017 \\
\hline 3 & 1,011 \\
\hline 4 & 1,008 \\
\hline 5 & 1,001 \\
\hline 6 & 1,000 \\
\hline 7 & 0,999 \\
\hline 8 & 0,999 \\
\hline 9 & 0,996 \\
\hline 10 & 0,991 \\
\hline
\end{tabular}

4.Support Vector Machines Berbasis

\section{Particle Swarm Optimizition}

Hasil penelitian ini menghasilkan Root Mean Squered Error (RMSE) dari algoritma Support Vector Machines Berbasis Particle Swarm Optimizition

Tabel Error! No text of specified style in document..2 Nilai RMSE

\begin{tabular}{|c|c|}
\hline X-validasi & RMSE \\
\hline 2 & 0,909 \\
\hline 3 & 0,908 \\
\hline 4 & 0,908 \\
\hline 5 & 0,900 \\
\hline 6 & 0,906 \\
\hline 7 & 0,905 \\
\hline 8 & 0,906 \\
\hline 9 & 0,904 \\
\hline 10 & 0,902 \\
\hline & \\
\hline
\end{tabular}

4.Hasil Perbandingan Algoritma

Support Vector Machine Biasa Dan Support Vector Machine Berbasis

Particle Swarm Optimization Untuk Prediksi Suhu Udara.

Berdasarkan hasil perbandingan antara Support Vector Machines dan Support Vector Machines Berbasis Particle
Swarm Optimizition pada tabel dibawah ini:

Tabel Error! No text of specified style in document.. 3 Nilai Perbandingan RMSE SVM DAN SVM - PSO

\begin{tabular}{|c|c|c|}
\hline X VALIDATION & $\begin{array}{l}\text { NILAI } \\
\text { RMSE(S } \\
\text { VM) }\end{array}$ & $\begin{array}{l}\text { NILAI RMSE(SVM- } \\
\text { PSO) }\end{array}$ \\
\hline 2 & 1,017 & 0,909 \\
\hline 3 & 1,011 & 0,908 \\
\hline 4 & 1,008 & 0,908 \\
\hline 5 & 1,002 & 0,900 \\
\hline 6 & 1,000 & 0,906 \\
\hline 7 & 0,999 & 0,905 \\
\hline 8 & 0,999 & 0,906 \\
\hline 9 & 0,996 & 0,904 \\
\hline 10 & 0,991 & 0,902 \\
\hline
\end{tabular}

3.Hasil yang paling akurat yang kecil yaitu svm (pso)

Nilai svm(pso) adalah dengan nilai RMSE 0,900 pada X-validasi 5 ternyata lebih akurat di bandingkan Svm biasa.

\section{KESIMPULAN}

Algoritma Support Vector Machines Berbasis PSO hasilnya lebih rendah RMSE nya dibandingkan dengan Support Vector Machines .Hasil RMSE untuk Support Vector Machines adalah 0,991.Sedangkan Hasil RMSE Support Vector Machines Berbasis PSO adalah 0,900 dengan demikian penulis mengusulkan agar menghasilkan prediksi yang lebih akurat dari penelitian ini, diperlukan penelitian tahap berikutnya dengan algoritma lainnya.Analisis dan perbandingan 
mengenai prediksi suhu udara dengan mengunakan berbagai algoritma ini hanya menempatkan akurasi (berdasar nilai error ) sebagai factor uji. Dari hal datang, untuk pengujian yang lebih baik perlu pengambilan data uji dalam jumlah yang lebih banyak lagi. Perlu melakukan pengujian dengan berbagai algoritma yang lain.

\section{DAFTAR PUSTAKA}

[1] B. B. Banjarmasin, K. Jembatan, and $\mathrm{M}$.

Banjarmasin, "Riset BMKG Kota Banjarmasin," BMKG Banjarmasin, vol. 15, no. 8, pp. 1-15, 2013.

[2] B. Susilo, "Study sebaran suhu dan RH Mesin Pengering Temperature and Humidity Distribution Study of Mocaf Chip Hybrid Dryer," Suhu Udara, vol. 13, no. 2, pp. 8896, 2012.

[3] M. Widiasri, A. Justitia, and A. Z. Arifin, "Penerapan Particle Swarm Optimization untuk Penentuan Parameter Regularisasi pada Kernel Regularized Discriminant Analysis," SVM-PSO, vol. 2011, no. Ies, pp. 978-979, 2011.

[4] S. Matematika, N. S. Pradipta, P. Sembiring, and P. Bangun, "suhu udara," cuaca iklim, vol. 1, no. 5, pp. 459-468, 2013.
[5] S. Syamsuar, "Model Autoregressive Untuk Suhu Udara Rata-Rata Bulanan Serang Banten," Warta $L A P A N$, vol. 2, no. 1, pp. 1623, 2010.

[6] I. H. Witten, E. Frank, and M. a. Hall, "Teori tentang Data Mining," Data Mining, vol. 277, no. 6, pp. 665-666, 2011.

[7] S. H. Liao, P. H. Chu, and P. Y. Hsiao, "Data mining techniques and applications A decade review from 2000 to 2011," Expert Systems with Applications, vol. 39, no. 12, pp. 11303-11311, 2012.

[8] L. I. P. Indonesia, "Pengertian Data Mining," Data Mining, vol. 7, no. 3, pp. 3-9, 2010.

[9] H. Xue, Q. Yang, and S. Chen, "SVM: Support Vector Machines," The Top Ten Algorithms in Data Mining, vol. 6 , no. 3 , pp. $37-60$, 2009.

[10] C. Tu, L. Chuang, J. Chang, and C. Yang, "Feature Selection using PSO-SVM," SVM-PSO, vol. 5, no. 8, pp. 36, 2007.

[11] M. Li and J. Zhang, "SVM OptimIzed Scheme Based PSO In Application Of," svm pso, no. July, pp. 12-15, 2009.

[12] C. Dewi, D. P. Kartikasari, and Y. T. Mursityo, "Prediksi CuacaTime Seres pada data 
time series mengguanakan

Adaptive Neuro Fuzzy System

(Anfis)," Prediksi Cuaca, vol.

1, no. 5, pp. 18-24, 2014.

[13] Daniel T. Larose, Data Mining

Methods and Models Larose., 2006.

[14] Dedy Suryadi Sani Susanto, Pengantar Data Mining:

Menggali Pengetahuan dari

Bongkahan Data., 2010.

[15] Tan Pang-Ning, Michael

Stienbach, and Vivin Kumar,

Introduction To Data Mining, J.

Taylor, Ed. Stanford, 2005.

[16] Budi Santosa, Data Mining:

Teknik Pemanfaatan Data

untuk Keperluan Bisnis.

Yogyakarta: Graha Ilmu, 2007. 